\title{
Usefulness of three-dimensional optical frequency domain imaging for diagnosing in-stent restenosis due to a stent fracture
}

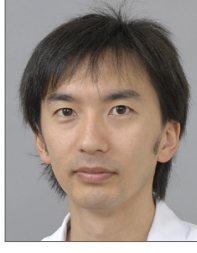

Yusuke Oba, MD; Nobuhiko Ogata*, MD, PhD; Motoki Fukutomi, MD, PhD; Kazuomi Kario, $\mathrm{MD}, \mathrm{PhD}$

Division of Cardiovascular Medicine, Department of Internal Medicine, Jichi Medical University School of Medicine, Tochigi, Japan

This paper also includes supplementary data published online at: http://www.pcronline.com/eurointervention/108th_issue/235

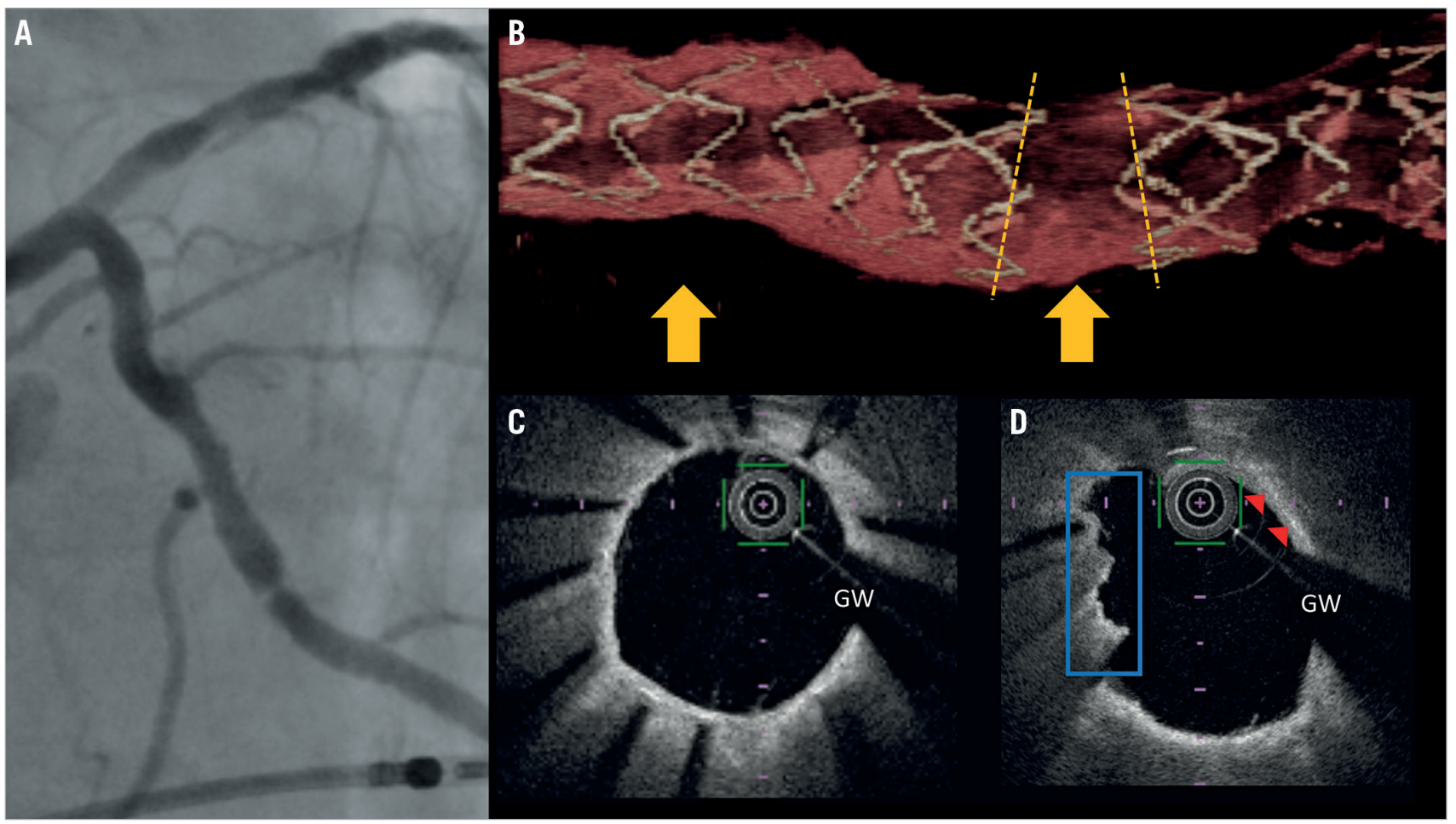

A 74-year-old man underwent a percutaneous coronary intervention $(\mathrm{PCI})$ due to worsening effort angina pectoris. We implanted a $3.0 \times 18 \mathrm{~mm}$ DES (Nobori $^{\circledR}$; Terumo Corp., Tokyo, Japan) in the left circumflex coronary artery (LCx). The final angiographic results were satisfactory for the targeted lesion. Thirty-three months later, coronary angiography revealed in-stent restenosis (Panel A, Moving image 1). After an angioplasty using a $3.0 \times 15 \mathrm{~mm}$ balloon (Lacrosse $^{\circledR}$ NSE ALPHA ${ }^{\mathrm{TM}}$; Goodman Co., Ltd, Nagoya, Japan), optical frequency domain imaging (OFDI) was performed. The multiple struts of the stent were completely fractured at the acquired transection with a gap in the stent body (Panel B, Moving image 2). Although Panel C shows circumferentially covered stent struts, superficial high-intensity high-attenuation plaque and a hazy appearance by OFDI might suggest accumulations of macrophage and mural thrombus on this fractured site (Panel D). Therefore, the main reason for in-stent restenosis in this case might be persistent mechanical stress due to total separation type stent fracture. Finally, an angioplasty was performed with a $3.0 \times 15 \mathrm{~mm}$ paclitaxel-coated balloon (SeQuent ${ }^{\circledR}$ Please; B. Braun, Melsungen, Germany).

\section{Acknowledgement}

We acknowledge the kind advice received from Dr Gaku Nakazawa.

\section{Conflict of interest statement}

The authors have no conflicts of interest to declare.

\section{Supplementary data}

Moving image 1. Follow-up angiography revealed in-stent restenosis in the LCx.

Moving image 2. 3-dimensional OFDI showed the total separation type stent fracture.

*Corresponding author: Division of Cardiovascular Medicine, Department of Internal Medicine, Jichi Medical University School of Medicine, 3311-1 Yakushiji, Shimotsuke, Tochigi, 329-0498, Japan.E-mail: ogatan@icloud.com 